\title{
Acetylation of aromatic ethers using acetic anhydride over solid acid catalysts in a solvent-free system. Scope of the reaction for substituted ethers
}

\author{
Keith Smith, ${ }^{* a}$ Gamal A. El-Hiti, $\dagger^{a} a$ Anthony J. Jayne ${ }^{a}$ and Michael Butters ${ }^{b}$ \\ ${ }^{a}$ Centre for Clean Chemistry, Department of Chemistry, University of Wales Swansea, \\ Singleton Park, Swansea, UK SA2 8PP \\ ${ }^{b}$ AstraZeneca, Global Process R\&D, Avlon Works, Bristol, UK BS10 7ZE
}

Received 3rd February 2003, Accepted 12th March 2003

First published as an Advance Article on the web 27th March 2003

The acetylation of aryl ethers using acetic anhydride in the presence of zeolites under modest conditions in a solvent-free system gave the corresponding para-acetylated products in high yields. The zeolite can be recovered, regenerated and reused to give almost the same yield as that given when fresh zeolite is used.

\section{Introduction}

Acetylation of aromatic compounds is an important tool for the synthesis of aromatic ketones, some of which are useful intermediates for the synthesis of valuable industrial and pharmaceutical compounds. This type of reaction is of interest in the field of aromatic substitution and displays high regioselectivity towards substitution in the para-position. Traditionally, such Friedel-Crafts acylations of aromatic compounds use acid chlorides or anhydrides in the presence of Lewis acid activators such as metal halides or Brønsted acids such as polyphosphoric and sulfuric acids. ${ }^{1-4}$ Unfortunately, use of such activators creates a number of environmental limitations. The activators may be needed in more than stoichiometric amounts because of complexation to the starting materials and/ or products. Work-up usually involves hydrolysis, which may lead to loss of the activator and generation of large amounts of corrosive and toxic waste products. Moreover, reactions are often not clean and lead to the production of mixtures of products with low selectivity.

Many efforts have therefore been made to develop a more environmentally friendly process for acylation reactions. The use of recoverable and regenerable solid catalysts can overcome many of the limitations associated with use of metal halide Lewis acids. Furthermore, use of zeolites can maximise the selectivity and yield of a single desired product, while minimising the formation of by-products. ${ }^{5-9}$ We have had success with the use of zeolites, which have the added advantage of providing para-regioselectivity, in nitration, ${ }^{10}$ bromination, ${ }^{11}$ chlorination, ${ }^{12}$ allylation, ${ }^{13}$ alkylation ${ }^{14}$ and methanesulfonylation ${ }^{15}$ reactions.

However, relatively little attention has been paid to the acylation of aromatic compounds in the presence of zeolites as catalysts. ${ }^{16}$ The recent disclosure of the commercial application of a procedure involving zeolite-catalysed acylation of aromatic ethers ${ }^{17}$ prompted us to report our own initial results in this area. ${ }^{18}$ We now report a study of the scope of the acetylation reactions for substituted aryl ethers. We have been able to achieve regioselective acetylation of a range of aryl ethers under modest conditions with acetic anhydride over zeolites.

\section{$\breve{r}$ Results and discussion}

We have previously shown that acetylation of anisole using acetic anhydride over $\mathrm{H} \beta(0.15 \mathrm{~g}$ per 5 mmole of anisole $)$ in the absence of solvent at $120^{\circ} \mathrm{C}$ for $2 \mathrm{~h}$ gave exclusively $p$-methoxy-

$\dagger$ Permanent address: Department of Chemistry, Faculty of Science, Tanta University, Tanta 31527, Egypt.
Table 1 Synthesis of 4-acetyl-2-chloroanisole (2) from reaction of 1 with $\mathrm{Ac}_{2} \mathrm{O}$ over $\mathrm{HY}(\mathrm{Si}: \mathrm{Al} \mathrm{40)}$ ) and $\mathrm{H} \beta(\mathrm{Si}: \mathrm{Al} 12.5)$ according to eqn. (1) ${ }^{a}$

\begin{tabular}{lll}
\hline Catalyst $^{b}$ & $t / h$ & ${\text { Yield }(\%)^{c}}^{c}$ \\
\hline H $\beta$ & 2 & 91 \\
H $\beta$ & 6 & 94 \\
HY & 2 & 75 \\
HY & 6 & 81 \\
HY & 24 & 84 \\
HY & 48 & 86
\end{tabular}

${ }^{a}$ A mixture of freshly calcined catalyst $(0.50 \mathrm{~g}), \mathrm{Ac}_{2} \mathrm{O}(1.23 \mathrm{~g}$, $12.0 \mathrm{mmol}), 1(1.42 \mathrm{~g}, 10.0 \mathrm{mmol})$ and hexadecane $(0.77 \mathrm{~g})$ was stirred at $120{ }^{\circ} \mathrm{C}$ for the stated reaction time. ${ }^{b}$ Zeolites were calcined at $400{ }^{\circ} \mathrm{C}$ prior to use. ${ }^{c}$ Yields were determined by GC analysis in the presence of hexadecane as added standard.

acetophenone in $98 \%$ yield. ${ }^{18}$ In order to investigate the scope of this reaction, we planned to study acetylation of disubstituted benzene derivatives using acetic anhydride as the acylating agent over suitable zeolite catalysts. Initial study was carried out on compounds having substituents with a modest influence on reactivity (halo and alkyl substituents).

We first examined the acetylation of 2-chloroanisole (1) with acetic anhydride over large pore zeolites HY ( $\mathrm{Si}: \mathrm{Al} 40)$ and $\mathrm{H} \beta$ ( $\mathrm{Si}: \mathrm{Al} 12.5)$ at $120^{\circ} \mathrm{C}$ for various reaction times (eqn. (1)). The reaction produced 4-acetyl-2-chloroanisole (2) almost exclusively. The yield of $\mathbf{2}$ obtained is shown in Table 1 .

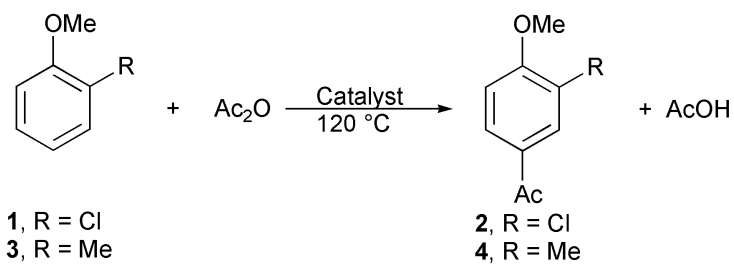

It is clear from the results recorded in Table 1 that the reaction successfully produced the acetylated product $\mathbf{2}$ in very good yield, which increased slightly as the reaction time increased. Compound 2 was obtained in 91 and $94 \%$ yield when the reaction was carried out over $\mathrm{H} \beta$ for 2 and $6 \mathrm{~h}$, respectively, while the yield of 2 was 75 and $86 \%$ when the reaction was carried out over HY for 2 and $48 \mathrm{~h}$, respectively.

Similarly, acetylation of 2-methylanisole (3), using acetic anhydride in the presence of a large pore zeolite ( $\mathrm{HY}$ or $\mathrm{H} \beta$ ) at $120{ }^{\circ} \mathrm{C}$ for $2 \mathrm{~h}$, was attempted (eqn. (1)). It was found that 
Table 2 Yields of products $\mathbf{6}$ and $\mathbf{7}$ from reaction of 5 with $\mathrm{Ac}_{2} \mathrm{O}$ over $\mathrm{HY}(\mathrm{Si}: \mathrm{Al} 40)$ and $\mathrm{H} \beta(\mathrm{Si}: \mathrm{Al} 12.5)$ according to eqn. (2)

\begin{tabular}{llll}
\hline & \multicolumn{3}{l}{ Yield (\%) $^{c}$} \\
\cline { 3 - 4 } Catalyst $^{b}$ & $t / h$ & $\mathbf{6}$ & $\mathbf{7}$ \\
\hline H $\beta$ & 2 & 61 & 18 \\
H $\beta$ & 4 & 69 & 23 \\
HY & 2 & 59 & 17 \\
HY & 4 & 65 & 21
\end{tabular}

${ }^{a}$ A mixture of freshly calcined catalyst $(0.50 \mathrm{~g}), \mathrm{Ac}_{2} \mathrm{O}(1.23 \mathrm{~g}$ $12.0 \mathrm{mmol}), 5(1.22 \mathrm{~g}, 10.0 \mathrm{mmol})$ and hexadecane $(0.77 \mathrm{~g})$ was stirred at $120{ }^{\circ} \mathrm{C}$ for the stated reaction time. ${ }^{b}$ See footnote $b$ to Table 1. ${ }^{c}$ See footnote $c$ to Table 1

acetylation of $3(10 \mathrm{mmol})$ with acetic anhydride $(12 \mathrm{mmol})$ over HY $(0.5 \mathrm{~g})$ at $120^{\circ} \mathrm{C}$ for $2 \mathrm{~h}$ gave 4-acetyl-2-methylanisole (4) in 79\% yield (eqn. (1)), with no more than trace quantities of isomeric products. Reaction under similar conditions over $\mathrm{H} \beta$ gave 4 in even better yield (87\%). Clearly, both zeolites HY and $\mathrm{H} \beta$ were effective for the reaction.

Attention was turned next to acetylation of 3-methylanisole (5) under conditions similar to those used to acetylate $\mathbf{3}$. However, reaction of 5 with acetic anhydride at $120^{\circ} \mathrm{C}$ over $\mathrm{HY}$ or $\mathrm{H} \beta$ for various reaction times led always to a mixture of two acetylated products 6 and 7 (eqn. (2)), the yields of which are recorded in Table 2.

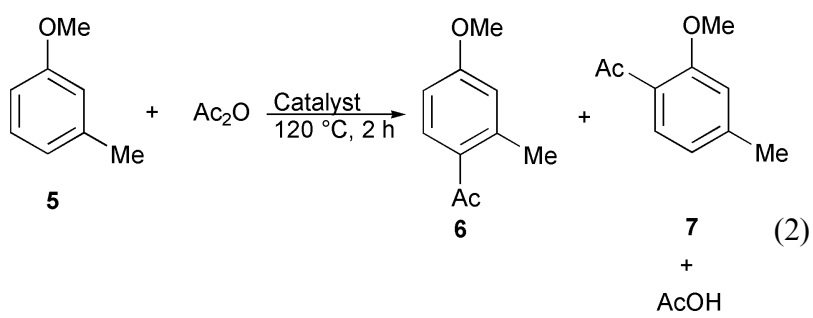

As can be seen from Table 2, the overall yields were very good over both $\mathrm{H} \beta$ and HY. A high overall yield $(92 \%)$ of 6 plus 7 was obtained after $4 \mathrm{~h}$ over $0.05 \mathrm{~g}$ of $\mathrm{H} \beta$ per mmol of substrate, while over HY under similar conditions the combined yield was also very good $(86 \%)$.

Samples of zeolites $\mathrm{HY}$ and $\mathrm{H} \beta$ that were recovered from the reactions depicted in eqns. (1) and (2) were regenerated by calcination at $400{ }^{\circ} \mathrm{C}$ and reused in reactions that were identical to the ones from which the samples were recovered. In all cases the yields were virtually the same.

Attention was next turned to investigation of regioselective acetylation of 2,3-dihydrobenzofuran (8). It was found that acetylation of $\mathbf{8}(10 \mathrm{mmol})$ using acetic anhydride $(12 \mathrm{mmol})$ over $\mathrm{H} \beta(\mathrm{Si}: \mathrm{Al} 12.5,0.5 \mathrm{~g})$ at $120^{\circ} \mathrm{C}$ for $1.5 \mathrm{~h}$ gave 5 -acetyl-2,3dihydrobenzofuran (9) in 95\% yield (eqn. (3)), with little evidence of isomeric products.

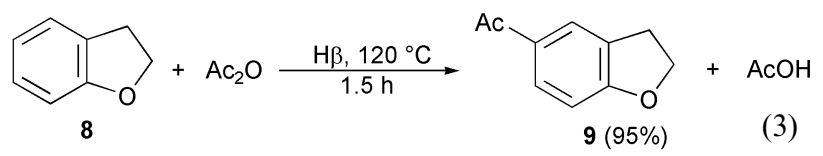

Attention was next turned to the acetylation of a deactivated aryl ether, ethyl 2-ethoxybenzoate (10). Acetic anhydride was used as the reagent in the presence of a range of heterogeneous catalysts including large pore zeolites $(\mathrm{H} \beta, \mathrm{HY}, \mathrm{H}-$ Mordenite and HX), a medium pore zeolite (HZSM-5), clays (K10, KSF and ENVIROCAT EPZG) and an amorphous silica-alumina (Synclyst 25), under reflux conditions for $3 \mathrm{~h}$ (eqn. (4)). A mixture of two significant products, characterised as $\mathbf{1 1}$ and 12, was obtained, along with residual 10. The yields are recorded in Table 3 .
Table 3 Products from reaction of $\mathbf{1 0}$ with $\mathrm{Ac}_{2} \mathrm{O}$ over different catalysts according to eqn. (4) ${ }^{a}$

\begin{tabular}{lrrr}
\hline & \multicolumn{2}{l}{${\text { Yield }(\%)^{c}}^{c}$} \\
\cline { 2 - 4 } Catalyst $(\mathrm{Si}: \mathrm{Al})^{b}$ & $\mathbf{1 0}$ & $\mathbf{1 1}$ & $\mathbf{1 2}$ \\
\hline H $\beta(12.5)$ & 76 & 5 & 14 \\
HY (60) & 65 & 21 & 5 \\
HY (40) & 68 & 19 & 4 \\
HY (30) & 69 & 19 & 4 \\
HY (12) & 73 & 14 & 4 \\
HY (5.2) & 84 & 6 & 4 \\
HX (1.5) & 96 & 0 & 1 \\
H-Mordenite (10) & 96 & 0 & 2 \\
HZSM-5 (25) & 96 & 0 & 2 \\
K10 & 84 & 6 & 2 \\
K10/A1 & & & \\
KSF & 87 & 4 & 3 \\
Synclyst 25 & 92 & 1 & 2 \\
ENVIROCAT EPZG & 98 & 0 & 2 \\
& 87 & 3 & 2
\end{tabular}

${ }^{a}$ A mixture of freshly calcined catalyst $(0.50 \mathrm{~g}), \mathrm{Ac}_{2} \mathrm{O}(1.23 \mathrm{~g}$, $12.0 \mathrm{mmol}), 10(1.94 \mathrm{~g}, 10.0 \mathrm{mmol})$ and hexadecane $(0.77 \mathrm{~g})$ was stirred under reflux for $3 \mathrm{~h} .{ }^{b}$ Zeolites and Synclyst were calcined at $400{ }^{\circ} \mathrm{C}$ and clays at $110{ }^{\circ} \mathrm{C}$ prior to use. ${ }^{c}$ See footnote $c$ to Table 1 .

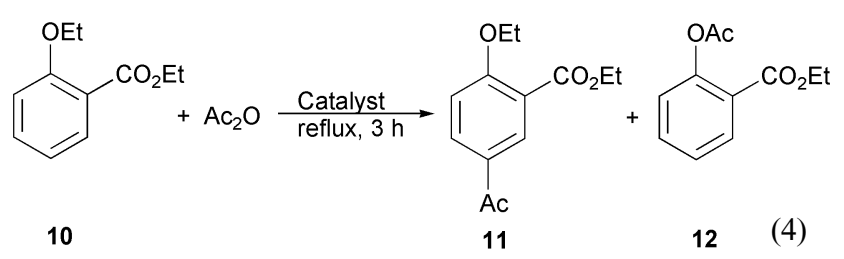

As the results in Table 3 demonstrate, the acetylation of $\mathbf{1 0}$ proceeds only slowly. It is clear that $\mathrm{HY}$ is the most effective of the catalysts tried, and within the series of $\mathrm{HY} / \mathrm{HX}$ catalysts tried, the reaction proceeds better as the $\mathrm{Si}$ : Al ratio increases, indicating that strength of the sites is more important than the number/abundance of acid sites. Compound $\mathbf{1 1}$ was obtained in 6 and $21 \%$ yields, respectively, when reaction was carried out over HY with $\mathrm{Si}$ : Al ratios 5.2 and 60. Therefore, the yield of desired product increased as the strength of acid sites increased (Table 3). Zeolite $\mathrm{H} \beta$ and $\mathrm{K} 10$ clay were also reactive, but gave lower yields of the desired product. It appears, therefore, that acidity and accessibility of sites are both important.

In all cases acetodealkylation of the ether also occurred. No such reaction had been observed during acetylation of aryl ethers containing alkyl or halo groups, so presumably the presence of the ethoxycarbonyl group was important in encouraging the process, perhaps by one of the mechanisms shown in Fig. 1. For some reason, zeolite $\mathrm{H} \beta$ particularly favoured this reaction.

A series of experiments involving zeolites $\mathrm{H} \beta$ ( $\mathrm{Si}$ : Al 12.5) and $\mathrm{HY}(\mathrm{Si}: \mathrm{Al} 40)$ as catalysts, over different reaction times, was conducted. The results obtained are recorded in Table 4. The yield of 11 was $31 \%$ when the reaction was carried out over HY $(1.0 \mathrm{~g})$ for $24 \mathrm{~h}$ under reflux conditions, while the yield of $\mathbf{1 1}$ was only $14 \%$ when the reaction was carried out over $\mathrm{H} \beta(0.5 \mathrm{~g})$ under similar reaction conditions. Therefore, the yield of the desired product was only slightly increased as the quantity of catalyst and reaction time were increased. However, when $\mathrm{H} \beta$ was used as the catalyst, the yield of the by-product $\mathbf{1 2}$ was greatly increased, to $66 \%$ for a reaction period of $24 \mathrm{~h}$.

Confirmation of the nature of the by-product, namely ethyl 2-acetoxybenzoate (12), was achieved by reaction between ethyl salicylate (13) and acetic anhydride over zeolite $\mathrm{H} \beta$ ( $\mathrm{Si}$ : Al $12.5,0.5 \mathrm{~g}$ for $10 \mathrm{mmol}$ of 13) at ambient temperature for $18 \mathrm{~h}$ (eqn. (5)). The reaction was allowed to proceed overnight, and the product was purified by flash column chromatography to give 12 in $66 \%$ yield. It was identical in all respects to the product from acetylation of $\mathbf{1 0}$. 
Table 4 Yields of products $\mathbf{1 1}$ and $\mathbf{1 2}$ from reaction of $\mathbf{1 0}$ with $\mathrm{Ac}_{2} \mathrm{O}$ over $\mathrm{H} \beta(\mathrm{Si}: \mathrm{Al} 12.5)$ or $\mathrm{HY}(\mathrm{Si}: \mathrm{Al} 40)$ under different reaction conditions, according to eqn. (4) ${ }^{a}$

\begin{tabular}{lrlrl}
\hline & \multicolumn{4}{l}{ Yield (\%) } \\
\cline { 3 - 5 } Catalyst $(\mathrm{g})^{b}$ & $t / \mathrm{h}$ & $\mathbf{1 0}$ & $\mathbf{1 1}$ & $\mathbf{1 2}$ \\
\hline H $\beta(0.5)$ & 6 & 29 & 14 & 53 \\
H $3(0.5)$ & 24 & 16 & 14 & 66 \\
HY $(0.5)$ & 6 & 69 & 24 & 4 \\
HY (1.0) & 6 & 65 & 28 & 4 \\
HY (0.5) & 24 & 65 & 27 & 4 \\
HY (1.0) & 24 & 61 & 31 & 5
\end{tabular}

${ }^{a}$ A mixture of freshly calcined catalyst, $\mathrm{Ac}_{2} \mathrm{O}(1.23 \mathrm{~g}, 12.0 \mathrm{mmol})$, $10(1.94 \mathrm{~g}, 10.0 \mathrm{mmol})$ and hexadecane $(0.77 \mathrm{~g})$ was stirred under reflux for the stated reaction time. ${ }^{b}$ See footnote $b$ to Table $1 .{ }^{c}$ See footnote $c$ to Table 1 .

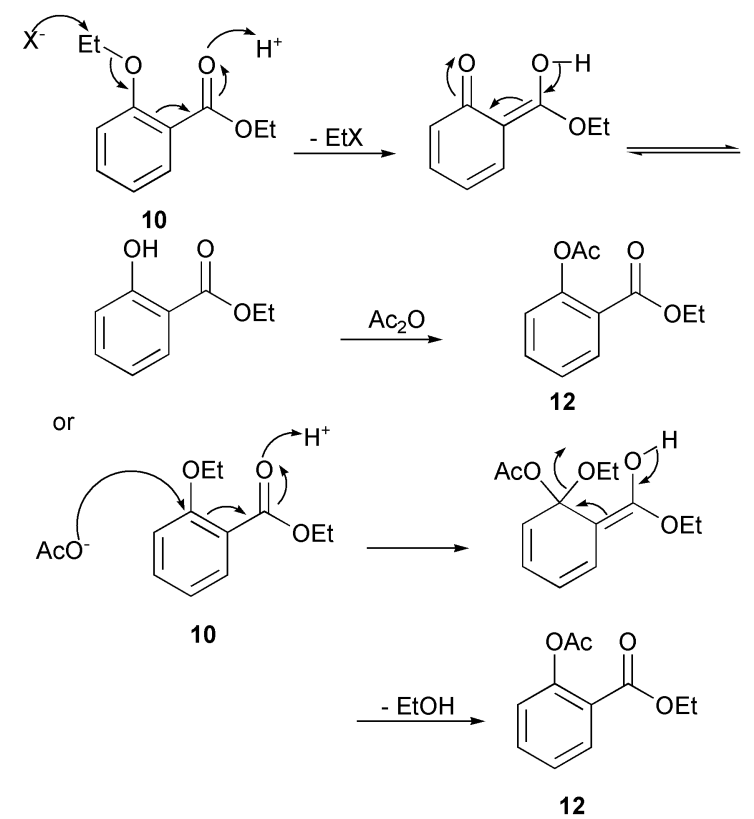

Fig. 1 Possible mechanisms for the acetodealkylation of $\mathbf{1 0 .}$

$$
\text { (5) }
$$

Our attention was next turned to acetylation of another deactivated ether, 2-ethoxybenzaldehyde (14). It was found that acetylation of 14 over $\mathrm{HY}$ ( $\mathrm{Si}: \mathrm{Al} 60,0.5 \mathrm{~g}$ ) at $120^{\circ} \mathrm{C}$ for $24 \mathrm{~h}$ gave the 1,1-diacetate derivative (15) in $10 \%$ isolated yield, along with recovered starting material 14 (eqn. (6)). Compounds such as $\mathbf{1 5}$ are generally produced when aldehydes are treated with anhydrides. It is clear that the presence of an aldehyde group has a deactivating influence on the aromatic ring, so that acetylation on the aromatic ring does not occur. Indeed, the reaction does not appear to be very useful at all for direct acetylation of deactivated aryl ethers.

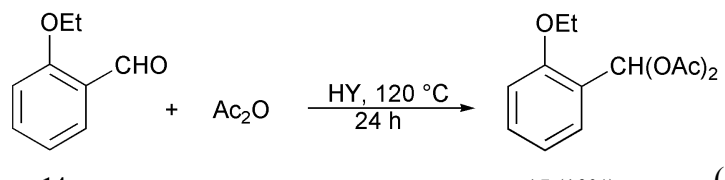

14

$15(10 \%)$

In order to assess the usefulness of the reaction for activated ethers, acetylation of 1,2-dimethoxybenzene (16) using acetic
Table 5 Yields of products $\mathbf{2 1}$ and $\mathbf{2 2}$ from reaction of $\mathbf{2 0}$ with $\mathrm{Ac}_{2} \mathrm{O}$ over HY (Si : $\mathrm{Al} 40)$ or $\mathrm{H} \beta(\mathrm{Si}: \mathrm{Al} 12.5)$ according to eqn. (8) ${ }^{a}$

\begin{tabular}{lll}
\hline Catalyst $^{b}$ & $t / \mathrm{h}$ & Yield $(\%)^{c}$ of $\mathbf{2 1}+\mathbf{2 2}$ \\
\hline $\mathrm{HY}$ & 1 & 90 \\
$\mathrm{H} \beta$ & 1 & 80 \\
$\mathrm{H} \beta$ & 2 & 89 \\
$\mathrm{H} \beta$ & 3 & 93
\end{tabular}

${ }^{a}$ A mixture of freshly calcined catalyst $(0.50 \mathrm{~g}), \mathrm{Ac}_{2} \mathrm{O}(1.23 \mathrm{~g}$, $12.0 \mathrm{mmol}), 20(1.52 \mathrm{~g}, 10.0 \mathrm{mmol})$ and hexadecane $(0.77 \mathrm{~g})$ was stirred at $120{ }^{\circ} \mathrm{C}$ for the stated reaction time. ${ }^{b}$ See footnote $b$ to Table 1 . ${ }^{c}$ See footnote $c$ to Table 1 .

anhydride over $\mathrm{H} \beta$ ( $\mathrm{Si}: \mathrm{Al} 12.5)$ and $\mathrm{HY}(\mathrm{Si}: \mathrm{Al} 60,0.5 \mathrm{~g}$ for $10 \mathrm{mmol}$ of 16 ) at $40{ }^{\circ} \mathrm{C}$ for $45 \mathrm{~min}$ was attempted. The corresponding regioselective para-acetylated product 17 was obtained in 74 and $91 \%$ yields, respectively, over the two zeolites. Similarly, acetylation of 1,2-diethoxybenzene (18) over $\mathrm{H} \beta$ and $\mathrm{HY}$ at $120{ }^{\circ} \mathrm{C}$ for $1 \mathrm{~h}$ afforded the corresponding para-acetylated product $\mathbf{1 9}$ in 78 and $91 \%$ yields, respectively (eqn. (7)).

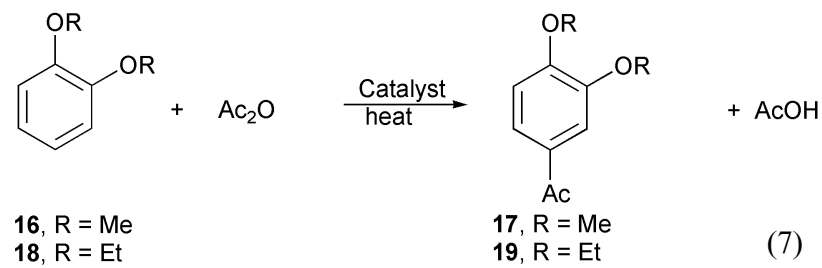

It was of interest to determine the major regioisomer formed in the acetylation reaction of the unsymmetrical ether, 2-ethoxyanisole (20), for which two major regioisomers, $\mathbf{2 1}$ and 22, might be expected (eqn. (8)). Indeed, acetylation of 20 using acetic anhydride over $\mathrm{HY}$ ( $\mathrm{Si}: \mathrm{Al} 60,0.5 \mathrm{~g}$ for $10 \mathrm{mmol}$ of 20) at $120{ }^{\circ} \mathrm{C}$ for $1 \mathrm{~h}$ gave two regioisomers 21 and 22 (eqn. (8)) in $90 \%$ overall yield. The overall yield of $\mathbf{2 1}$ and $\mathbf{2 2}$ was $93 \%$ when the reaction was carried out at $120{ }^{\circ} \mathrm{C}$ for $3 \mathrm{~h}$ over $\mathrm{H} \beta$ ( $\mathrm{Si}$ : Al 12.5) (Table 5)

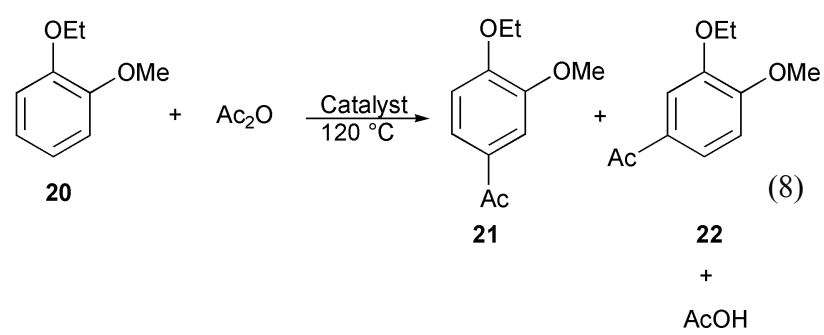

Due to similarities in the chemical nature of the substituent groups, separation of the two regioisomers proved to be extremely difficult. However, the NMR spectra of the mixtures indicated that the ratio of $21: \mathbf{2 2}$ was approximately $6: 4$ in all cases.

It is clear from the results recorded in Table 5 that the presence of an additional functional group in one of the positions ortho to the alkoxy group, and the relatively large size of the acetyl group, renders the remaining position ortho to the alkoxy group hindered to acetylation. Therefore, the position para to the alkoxy group is the major available site for electrophilic attack on the aromatic ring. However, in the case of acetylation of 2-ethoxyaniline (23) with acetic anhydride over HY ( $\mathrm{Si}$ : Al $60,0.5 \mathrm{~g}$ ) at room temperature for $10 \mathrm{~min}$, reaction unsurprisingly occurs preferentially on the amino group ortho to the ethoxy group, to give $\mathrm{N}$-acetylated product $\mathbf{2 4}$ in $92 \%$ yield (eqn. (9)).

Similarly, acetylation of 2-ethoxybenzyl alcohol (25) under similar reaction conditions gave $O$-acetylated product (26) in $88 \%$ yield (eqn. (10)). 


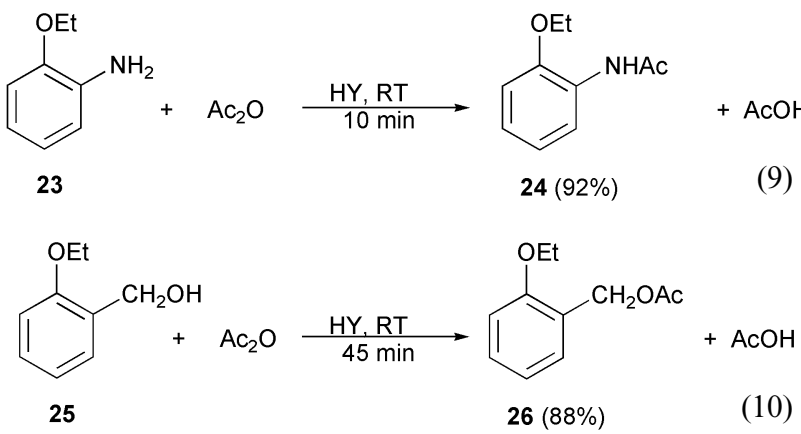

Clearly, acetylation occurs very rapidly at the hydroxyl and amino groups as opposed to the position on the aromatic ring para to the alkoxy group. A lone pair of electrons on $\mathrm{N}$ or $\mathrm{O}$ attacks the acetylating agent to produce amide or benzyl ester rather than the archetypical Friedel-Crafts acetylation product, the aromatic ketone.

\section{Conclusion}

Acetylation of aromatic ethers substituted by single groups with a modest effect on reactivity over zeolite $\mathrm{H} \beta$ or $\mathrm{HY}$ is a successful method that is highly selective for the position para to the alkoxy group. Deactivating groups cause considerable slowing of the reaction and it is better to use the more open and more active $\mathrm{HY}$ as catalyst. However, in such cases, reaction can proceed to give modest yields of product, though with some replacement of OR by OAc. In the presence of activating groups such as OR, reaction proceeds rapidly and offers quantitative reactions. Some selectivity for acylation para to the bulkier of the two alkoxy groups is apparent over $\mathrm{H} \beta$ or $\mathrm{HY}$, but such selectivity is not great. Aldehyde, hydroxyl and unsubstituted amino groups are not tolerated, reacting instead to give 1,1-diacetate, $O$ - or $\mathrm{N}$-acetylated products, respectively.

The solid catalysts can be recovered and reused, with the avoidance of toxic waste generated by traditional Lewis acid catalysts. This makes the process environmentally and commercially attractive.

\section{Experimental}

Commercially available starting materials (Aldrich) were used as supplied. Acetic anhydride (Aldrich, 99\%) was refluxed overnight over $\mathrm{P}_{2} \mathrm{O}_{5}$ and distilled under dry $\mathrm{N}_{2}$. Commercial zeolites were purchased from Aldrich Chemical Company or provided as gifts by Zeolyst International. All solids were freshly calcined prior to use by heating in air at $400{ }^{\circ} \mathrm{C}$ for a minimum of $6 \mathrm{~h}$ and cooled to room temperature in a desiccator over silica gel. A PU 4400 Gas Chromatograph (Philips) fitted with an RTX-1 fused silica capillary column $(30 \mathrm{~m} \times$ $0.32 \mathrm{~mm}$ ID) with dimethylpolysiloxane bonded phase was used for GC. Hexadecane was added as an internal standard to allow quantification. ${ }^{1} \mathrm{H}$ and ${ }^{13} \mathrm{C}$ NMR spectra were recorded on a Bruker $\mathrm{AC}$ spectrometer operating at $400 \mathrm{MHz}$ for ${ }^{1} \mathrm{H}$ and $100 \mathrm{MHz}$ for ${ }^{13} \mathrm{C}$ measurements. Low-resolution mass spectra were recorded on a VG 12-253 spectrometer, electron impact (EI) at $70 \mathrm{eV}$ and chemical ionization (CI) by the use of ammonia as ionization gas.

\section{Typical reaction procedure}

Quantities are recorded in the footnotes of the appropriate tables. All reactions were carried out in a $25 \mathrm{ml}$ round bottomed flask fitted with a magnetic stirrer. Freshly calcined solid catalyst, acetic anhydride $(1.23 \mathrm{~g}, 12.0 \mathrm{mmol})$ and aromatic substrate $(10 \mathrm{mmol})$ were added. Reaction was stirred at the appropriate temperature for the appropriate reaction time in a solvent-free system. The reaction mixture was diluted with ether or $\mathrm{CH}_{2} \mathrm{Cl}_{2}$, then filtered under vacuum and the filtrate was washed with distilled water $(2 \times 25 \mathrm{ml})$ and saturated $\mathrm{NaHCO}_{3}$ solution $(2 \times 25 \mathrm{ml})$. The organic layer was dried $\left(\mathrm{MgSO}_{4}\right)$, filtered and the solvent evaporated under reduced pressure. Quantitative analysis was achieved for the product mixture by GC. The product was purified by column chromatography and further purification was achieved by recrystallisation when necessary. Confirmation of the identity of product was achieved from NMR and mass spectral data.

\section{Acknowledgements}

We thank the University of Wales Swansea, Pfizer Central Research and the EPSRC for financial support, and the EPSRC Mass Spectrometry Centre at Swansea for mass spectra. We also thank the EPSRC, the Higher Education Funding Council for Wales (ELWa-HEFCW) and the University of Wales Swansea for grants that enabled the purchase and upgrading of NMR equipment used in the course of this work, and Zeolyst International for gifts of zeolites. G. A. El-Hiti thanks the Royal Society of Chemistry for an international author grant.

\section{References}

1 Friedel-Crafts Chemistry, ed. G. A. Olah, Wiley-Interscience, New York, 1973.

2 M. Spagnol, L. Gilbert and D. Alby, in The Roots of Organic Development, eds. J. R. Desmurs and S. Rattoy, Elsevier, Amsterdam, 1996, p. 29.

3 T. Mukaiyama, T. Ohno, T. Nishimura, S. Suda and S. Kobayashi, Chem. Lett., 1991, 1059.

4 K. Suzuki, H. Kitagawa and T. Mukaiyama, Bull. Chem. Soc. Jpn., $1993, \mathbf{6 6}, 3729$.

5 M. Butters, in Solid Supports and Catalysts in Organic Synthesis, ed. K. Smith, Ellis Horwood, Chichester, 1992, pp. 130-170.

6 Principles and Practice of Heterogeneous Catalysis, eds. J. M. Thomas and W. J. Thomas, VCH, Weinheim, 1997.

7 Catalysis of Organic Reactions using Supported Inorganic Reagents, ed. J. H. Clark, VCH, New York, 1994.

8 Introduction to Zeolite Science and Practice, ed. H. Van Bekkum, E. M. Flanigan and J. C. Jansen, Stud. Surf. Sci. Catal., 1991, vol. 58 .

9 J. H. Clark, S. R. Cullen, S. J. Barlow and T. W. Bastock, J. Chem. Soc., Perkin Trans. 2, 1994, 1117.

10 K. Smith, K. Fry, M. Butters and B. Nay, Tetrahedron Lett., 1989, 30, 5333; K. Smith, A. Musson and G. A. DeBoss, J. Org. Chem., 1998, 63, 8448; K. Smith, S. Almeer and S. J. Black, Chem. Commun., 2000, 1571; K. Smith, T. Gibbins, R. W. Millar and R. P. Claridge, J. Chem. Soc., Perkin Trans. 1, 2000, 2753; K. Smith, S. Almeer and C. Peters, Chem. Commun., 2001, 2748; K. Smith, S. Almeer, S. J. Black and C. Peters, J. Mater. Chem., 2002, 12, 3285.

11 K. Smith and D. Bahzad, Chem. Commun., 1996, 467; K. Smith, P. He and A. Taylor, Green Chem., 1999, 1, 35; K. Smith, G. A. El-Hiti, M. E. W. Hammond, D. Bahzad, Z. Li and C. Siquet, J. Chem. Soc., Perkin Trans. 1, 2000, 2745.

12 K. Smith, M. Butters and B. Nay, Synthesis, 1985, 1157; K. Smith, M. Butters, W. E. Paget, D. Goubet, E. Fromentin and B. Nay, Green Chem., 1999, 1, 83.

13 K. Smith and G. Pollaud, J. Chem. Soc., Perkin Trans. 1, 1994, 3519.

14 K. Smith and S. D. Roberts, Catal. Today, 2000, 60, 227.

15 K. Smith, G. M. Ewart and K. R. Randles, J. Chem. Soc., Perkin Trans. 1, 1997, 1085.

16 B. Chiche, A. Finiels, C. Gauthier, P. Geneste, J. Graille and D. Pioch, J. Org. Chem., 1986, 51, 2128; B. Chiche, A. Finiels, C. Gauthier and P. Geneste, Appl. Catal., 1987, 30, 365; B. Chiche, A. Finiels, C. Gauthier, P. Geneste, J. Graille and D. Pioch, J. Mol. Catal., 1987, 42, 229; C. Gauthier, B. Chiche, A. Finiels and P. Geneste, J. Mol. Catal., 1989, 50, 219; A. Corma, M. J. Climent, H. Garcia and J. Primo, Appl. Catal., 1989, 49, 109; D. E. Akporiaye, K. Daasvatn, J. Solberg and M. Stöcker, Stud. Surf. Sci. Catal., 1993, 78, 521; I. Neves, F. Jayat, P. Magnoux, G. Pérot, F. R. Ribeiro, M. Gubelmann and M. Guisnet, J. Mol. Catal., 1994, 93, 169; K. Gaare and D. E. Akporiaye, J. Mol. Catal., 1996, 109, 177; J. M. Escola and M. E. Davis, Appl. Catal. A, 2001, 214, 111; A. E. W. Beers, T. A. Nijhuis, F. Kapteijn and J. A. Moulijn, Microporous Mesoporous Mater, 2001, 48, 279; C. Castro, A. Corma and J. Primo, J. Mol. Catal. A, 2002, 177, 273; C. P. Bezouhanova, Appl. Catal. A, 2002, 229, 127. 
17 M. Spagnol, L. Gilbert, R. Jacquot, H. Guillot, P. J. Tirel and A.-M. Le Govic, Abstract P1, pp. 91-92 in the Book of Abstracts of the Fourth International Symposium on Heterogeneous Catalysis and Fine Chemicals, Basel, Switzerland, September 8-12, 1996; see also M. Spagnol, E. Benazzi and C. Marcilly, US Pat, 1998, 5,817,878.
18 K. Smith, Z. Zhenhua and P. K. G. Hodgson, J. Mol. Catal. A, 1998, 134, 121; see also K. Smith, Z. Zhenhua, L. Delaude and P. K. G. Hodgson, Abstract P018, pp. 62-63 in the Book of Abstracts of the Fourth International Symposium on Heterogeneous Catalysis and Fine Chemicals, Basel, Switzerland, September 8-12, 1996. 